\title{
La flora española: una riqueza en biodiversidad de primer orden aún en exploración. El proyecto Flora Ibérica
}

\author{
Santiago Castroviejo $(\dagger)^{1}$
}

Sumario: I. ¿POR QUÉ TENEMOS QUE DAR NOMBRE A LOS SERES VIVOS? II. LA TAXONOMÍA DE NUESTRA RICA BIODIVERSIDAD VEGETAL, UNA TAREA AÚN POR COMPLETAR. III. EL ORIGEN DE NUESTRA FLORA. 1.Flora canaria. 2. Peculiaridades: endemismo y xenófitos. IV. NUESTRA FLORA EN COMPARACIÓN CON LA DE OTROS PAÍSES. V. HACIA EL CONOCIMIENTO DE LA RIQUEZA REAL DE NUESTRA FLORA. VI. COROLARIO.

\section{I. ¿POR QUÉ TENEMOS QUE DAR NOMBRE A LOS SERES VIVOS?}

¿Puede alguien imaginarse un país en el que sus ciudadanos no tengan nombre? ¡Imposible! El nombre es la percha de la que se "cuelga" toda la información -derechos, domicilio, títulos, obligaciones, etc.- que afecta a cada uno de los individuos. Hasta tal punto es imprescindible el nombre que cuando dos de ellos coinciden, se buscan datos adicionales -identidad de los padres, fecha y lugar de nacimiento, etc.para no confundir a las personas que lo llevan. Para zanjar ese problema, los humanos hemos creado un sistema artificial que consiste en que a cada individuo se le adjudica un nombre dividido en dos partes: una, los apellidos, indica su relación con los padres y otra, el nombre de pila, lo individualiza.

Con los restantes seres vivos el problema es similar. La diferencia estriba en que en lugar de dar nombre a los individuos, damos nombre a las especies, lo cual, como veremos, implica un grado de complejidad muy elevado. Para que todo funcionase bien, deberíamos saber cuántas especies hay y como se distinguen unas de otras. Pero ese problema es extremadamente complejo y los diferentes científicos que han intentado calcularlo han aportado cifras tan dispares que lo único que sabemos es que lo que falta por descubrir es mucho más de lo que ya hemos descubierto hasta ahora, es

1 Profesor de Investigación del CSIC en el Real Jardín Botánico y miembro de la Real Academia de Ciencias, ha sido Coordinador general del proyecto Flora ibérica. 
decir, lo que se descubrió a lo largo de 250 años. En el cuadro 1 se ofrece una síntesis hecha por Kelly ${ }^{2}$ acerca del número de especies conocidas en cada grupo de seres vivos y las que faltan por conocer (se ofrecen las cifras de tres estimaciones, la más baja, la más alta y la que al autor le parece razonable).

\begin{tabular}{|l|r|r|r|r|r|r|}
\hline & $\begin{array}{c}\text { Prokariotes } \\
\text { Bacteria } \\
\text { \& Archea }\end{array}$ & $\begin{array}{c}\text { Protoctista } \\
\text { Protozoa } \\
\text { \& Algae }\end{array}$ & Fungi & Plantae & Animalae & Viruses \\
\hline Ya descritas & 4.000 & 80.000 & 72.000 & 270.000 & 1.320 .000 & 5.000 \\
\hline $\begin{array}{l}\text { Estimación más } \\
\text { baja }\end{array}$ & 50.000 & 250.000 & 200.000 & 300.000 & 2.825 .000 & 50.000 \\
\hline Cifra aceptable & 1.100 .000 & 600.000 & 1.500 .000 & 320.000 & 9.800 .000 & 500.000 \\
\hline Estimación más alta & 3.000 .000 & 1.200 .000 & 2.700 .000 & 500.000 & 103.255 .000 & 1.000 .000 \\
\hline $\begin{array}{l}\text { Grado de } \\
\text { conocimiento }\end{array}$ & Muy pobre & Muy pobre & Moderado & Bueno & Bueno o pobre & Muy pobre \\
\hline
\end{tabular}

Todas esas especies han de estar ordenadas de acuerdo con una clasificación y de llevar un nombre que debe tener estabilidad; es decir, el nombre no debería cambiar con el paso del tiempo.

Muchas veces no se comprende que la clasificación sea tan importante pero, de hecho, resulta imprescindible incluso para estructurar nuestro pensamiento. Para demostrarlo, el conocido escritor francés, Michel Foucault en su obra Les mots et les choses, citaba un párrafo que Jorge Luis Borges había publicado en Otras inquisiciones y que decía así: "Cierta enciclopedia china en la que está escrito que los animales se dividen en a) pertenecientes al Emperador, b) embalsamados, c) amaestrados, d) lechones, e) sirenas, f) fabulosos, g) perros sueltos, h) incluidos en esta clasificación, i) que se agitan como locos, j) innumerables, $k$ ) dibujados con un pincel finísimo de pelo de camello, I) etcétera, $m$ ) que acaban de romper el jarrón, n) que de lejos parecen moscas" A nadie se le escapa que con esa clasificación no hay modo de saber como son los animales.

Así pues, reconocer las especies, darles un nombre adecuado, clasificarlas y aportar datos de todo tipo sobre ellas es la tarea de una disciplina llamada taxonomía. Por la complejidad y tamaño de los grupos biológicos, el taxónomo se enfrenta a una tarea difícil, en la que tiene que trabajar, muchas veces, con material escaso o deficiente. De ahí que las conclusiones a las que llegan dos taxónomos diferentes al estudiar un mismo grupo no siempre coinciden. Lo cual, a su vez, crea desconcierto entre los usuarios de la taxonomía, que no comprenden como no se ha descubierto

242000 ]. $\quad$ K. Kelly. [All Species Inventory. A call for the discovery of all life-forms on Earth. Whole Earth, Fall 
todavía un método para distinguir unas especies de otras. Pero el tal método no existe, ni con toda probabilidad pueda existir nunca, porque los diferentes grupos de seres vivos son tan heterogéneos que los criterios que se siguen para separar las especies en unos no sirven para otros. Si a ello añadimos que no siempre se dispone de material suficiente para el estudio -seres escasos que habitan en lugares de difícil acceso- comprenderemos que pensar en una rápida solución del problema está lejos de nuestro alcance.

Lo verdaderamente importante es que detrás de cada nombre debe haber una especie, que vive en poblaciones naturales, en un área determinada y en un hábitat concreto. Este nombre, correctamente aplicado, permite crear teoría y relacionar hechos, situaciones y circunstancias. Gracias a ello sabemos mucho de muchas especies diferentes, información que permite, por ejemplo a los responsables del medio natural gestionar adecuadamente al conjunto de especies.

Todo sería correcto siempre que los nombres se apliquen con rigor. Por desgracia esto no siempre es así, ya que como consecuencia de la dificultad de conocer las especies, muchos gestores del medio y otros profesionales, en ocasiones, usan listas de nombres, en lugar de listas de especies.

Dos botánicos checos, J. Kirschner y Z. Kaplan, especialistas en el estudio de los juncos en el mundo, publicaron en la revista Taxon ${ }^{3}$ los resultados de una revisión de las juncáceas y potamogetonáceas que aparecen en la edición de 1997 del libro rojo de la Unión Internacional para la Conservación de la Naturaleza -“IUCN Red List of Threatened Plants"-. Compararon los nombres de las especies de ambas familias con la información presentada por las recientes monografías hechas por taxónomos, relativas a dichas familias. La conclusión del análisis es demoledora, pues encontraron que: a) una parte sustancial de los nombres de la Lista Roja de la IUCN son sinónimos que generalmente corresponden a plantas ampliamente distribuidas, que no están amenazadas por riesgo alguno de extinción; b) otros son nombres de aplicación dudosa, o sea que no se sabe a qué planta corresponden y, por último c) solo un 10-25\% de los nombres podrían incluirse en una Lista Roja sensata. Concluyen diciendo que la comparación muestra claramente la importancia de las monografías taxonómicas detalladas ... para la gestión de los recursos botánicos del mundo.

A pesar de que hay otros grupos de seres vivos mucho mejor estudiados, a los que se les ha dedicado más tiempo y más recursos, y cuyos datos son muy fiables, he querido poner este ejemplo para ilustrar la imperiosa necesidad de continuar trabajando también en el conocimiento y la taxonomía de la biodiversidad en todas sus dimensiones y manifestaciones, aún cuando hoy parece que se preste más atención a otras actividades relativas a su protección y gestión, que hace tan sólo unas décadas parecían menos urgentes.

3 Taxon. [vol. 51: 155-158 (2002)]. 


\section{LA TAXONOMÍA DE NUESTRA RICA BIODIVERSIDAD VEGETAL, UNA TAREA AÚN POR COMPLETAR}

En España, por razones que no vienen ahora al caso, en el terreno de las investigaciones botánicas nos movemos desacompasados con respecto a la mayor parte de los países europeos. Mientras que en los más desarrollados, las investigaciones taxonómicas están siendo relegadas por aquellas que se realizan en el campo de la ecología, la biología floral, la biología de la reproducción, la biología evolutiva, etc. nosotros estamos todavía elaborando nuestro catálogo florístico nacional y nuestra primera flora moderna. Nos encontramos en el final de una época de auge de los estudios botánicos en general y taxonómicos o florísticos en particular.

Resulta contradictorio que mientras se habla con interés creciente y generalizado de la Diversidad Biológica -es término frecuente incluso en la jerga política-, los estudios taxonómicos reciben cada vez menos apoyo y la taxonomía deja de ser considerada por muchos como una especialidad científica de vanguardia. Todo ello mientras los cálculos más optimistas indican que todavía desconocemos la identidad de más de un millón de organismos -entre ellos 50-100.000 plantas vasculares-, de los que más del 40\% no llegaremos jamás a conocer, porque desaparecerán antes de que lleguen a las manos del científico capaz de reconocerlo, describirlo y darle un nombre.

En la práctica, ya hoy se están describiendo especies de plantas a partir de las colecciones antiguas. Los esfuerzos por volver a encontrarlas no dieron fruto y se cree que el único testimonio que queda de la presencia de esa especie en nuestro planeta es ya esa exigua muestra guardada en una colección científica (herbario) y recolectada en su día por puro azar.

La taxonomía, recordemos, es el campo de la ciencia que se ocupa del estudio de los organismos vivos y sus relaciones de parentesco (evolución), es por tanto una especialidad básica en el estudio de la biodiversidad y herramienta imprescindible para su protección.

Nadie duda de que el objetivo más urgente del estudio de la diversidad biológica es, hoy en día, identificar y conocer lo organismos que la componen. La urgencia de esta tarea de recolección, estudio, catálogo, descripción y nomenclatura parece clara. Entonces, ¿por qué no se avanza en este camino al ritmo deseable o, siquiera, al mantenido por las escuelas alemana, británica y norteamericana hasta el último tercio del siglo XX? La respuesta es clara para muchos: "no se invierte lo suficiente". La explicación se nos antoja simplista. Por alguna razón no se invertirá suficiente.

Para los científicos naturalistas, la actividad exploradora y recolectora tuvo su apogeo en la segunda mitad del siglo XIX y primer tercio del XX. Actualmente, los avances en el campo de la biología celular, biología molecular, bioquímica, etc. supo26 nen para los jóvenes investigadores en biología un foco de atracción mucho más fuer- 
te. El prestigio alcanzable en esos terrenos hace que los mejores talentos -exceptuando los vocacionales- se dirijan hacia ellos.

En España, como hemos dicho, la botánica y la zoología se encuentran quizás en el momento álgido de los siglos XIX-XX. Cualquier parámetro de medida que usemos nos demostrará que nunca se invirtió tanto dinero, nunca hubo tantos profesionales dedicados a la investigación, nunca se publicó tanto, etc. Pero a pesar de todo ello distamos mucho de poder decir que conocemos bien nuestro medio natural (o nuestra diversidad biológica).

Las razones son esencialmente tres: a) la riqueza y diversidad de nuestro medio natural, b) el retraso histórico en este tipo de investigaciones, c) la escuela botánica española de la posguerra que -salvo muy honrosas excepciones- se ocupó sólo marginalmente de la taxonomía.

Analizando los dos primeros factores en el dominio de las plantas vasculares, nos encontramos que, hacia mediados del siglo XX, mientras la mayoría de los países europeos (incluido naturalmente Portugal) ya habían escrito diversas versiones de sus floras nacionales y muchas otras regionales o provinciales, en España la única obra que merece este calificativo (Prodromus Florae Hispanicae, insularunque Balearium) fue escrita entre 1878 y 1891 por un autor austríaco, Mauritius Willkomm, en colaboración con un danés, John Lange.

Mientras en casi toda Europa la recolección está básicamente concluida -la flora de su territorio está bien representada en la colecciones científicas (herbarios)- en España estamos descubriendo especies nuevas y nuevas áreas de un modo continuo.

Tenemos pues una flora compleja y todavía mal conocida. Las razones de esa complejidad hemos de buscarlas en la propia historia de nuestras plantas.

\section{EL ORIGEN DE NUESTRA FLORA}

Una ojeada a la historia del mundo vegetal es una ojeada a la lucha de las plantas por conquistar nuevos territorios y soportar condiciones diferentes, cada vez más duras, que les permitan competir con mayor ventaja, especialmente frente al calor y la sequía. Aunque la Tierra tiene c. 4.600 millones de años, la flora terrestre se empezó a formar hace solo 400-350 millones de años (Devónico), en un ambiente en el que gozaba un clima estable, húmedo y cálido. En esas condiciones las plantas, postradas al sustrato, sin consistencia para erguirse, comenzaron a producir lignina, una sustancia que endurece la pared celular, lo cual les dio una ventaja trascendente cara a su futuro.

Con una pared rígida, las células se superpusieron, dieron consistencia a los tallos, empezaron a formar los vasos conductores de la savia y las plantas, hasta 
entonces necesariamente tendidas sobre el sustrato, pudieron erguirse y colonizar el ambiente aéreo. Es decir, empezaron entonces a independizarse del agua. Así, aparecieron en esa época los briófitos, los helechos, las progimnospermas y pteridospermas, que dieron lugar ya a paisajes similares a los actuales, con bosques, etcétera.

Bastante más adelante, final del Pérmico-Triásico medio (hace 240-200 m.a.), Pangea -único continente existente entonces- se rompe, comienza la deriva de las placas continentales, la formación de la cadenas de montañas, la diversificación del clima, etc. Gracias a ello, las plantas se van encontrando con nuevos escenarios ambientales, lo que permite que los cambios evolutivos les abran enormes posibilidades de colonización y supervivencia. Previamente, ¿quizá por un impacto de meteorito?, se había producido una brutal sequía que implicó la desaparición y carbonización de enormes extensiones de bosque.

Hace ya 135-120 millones de años, aparecen las angiospermas, que son las plantas más abundantes hoy. Su éxito se basa en que han conseguido proteger los primordios seminales (equivalente a los óvulos de los animales) de la sequía mediante un ovario bien desarrollado, han conseguido además una enorme eficiencia en la fecundación produciendo flores hermafroditas y utilizando para este fin a los insectos (entomofilia); han conseguido además producir unas semillas que soportan todas las malas condiciones imaginables.

Desde hace 100 millones de años, la flora de la Tierra es biológicamente similar a la actual. A partir de aquí, esa flora -que soporta la gran extinción que acaba con los dinosaurios, hace 65 millones de años-, no deja de evolucionar para adaptarse a las nuevas condiciones que nuestro planeta va creando en cada uno de sus rincones, formados a su vez por la deriva de las placas continentales.

Por lo que ya nos afecta a nosotros de un modo directo, destacaremos que, en el período comprendido entre 15-5 millones de años atrás (Mioceno), Europa y África estaban separadas por el mar, con un clima relativamente húmedo. Pero pronto, una fuerte sequía unida a la basculación de la Península hacia el W-consecuencia de la orogenia alpina- provocan el contacto entre ambos continentes -cierre del estrecho de Gibraltar-, con lo que el Mediterráneo, que había pasado a ser un enorme lago, se deseca y se convierte en una depresión salina. Las plantas entonces pueden migrar fácilmente del $\mathrm{N}$ al $\mathrm{S}$ y de $\mathrm{W}$ al $\mathrm{E}$, colonizando nuevos territorios y encontrando unas condiciones adecuadas para que muchas formas desaten una activa especiación.

Al tiempo que muchas especies de nuestra flora del Terciario acaban desapareciendo por su incapacidad para soportar las condiciones de fuerte sequía y elevada temperatura que se van creando -algunas especies de esa flora artoterciaria subsisten incluso hasta nuestros días-, llegan entonces hasta nuestra Península además de 28 especies esteparias asiáticas, otras del Mediterráneo oriental, del N de África, etc. 
En esas condiciones, nos acercamos a los dos acontecimientos que más influencia habrían de tener en la formación de nuestra flora actual, a) la reapertura del Estrecho de Gibraltar y b) la llegada de las glaciaciones. La primera forzó aislamiento de nuestras plantas frente a sus congéneres magrebíes, nuestra Península pasó a convertirse en un "culo de saco" en el que las especies quedaban atrapadas sin poder escapar hacia el sur, lo que hizo que muchas evolucionasen hasta convertirse en nuevas. Por su parte, las glaciaciones, el segundo acontecimiento, implicaron una serie de migraciones alternativas de las plantas de toda Europa desde el $\mathrm{N}$ hacia el $\mathrm{S}$ y el $\mathrm{S}$ al $\mathrm{N}$, empujadas por las respetivas olas de frío y las de calor. Esas plantas, en plena migración, al tropezar con cualquiera de las muchas cadenas montañosas que jalonaban su camino, reaccionaron básicamente de tres formas: a) se extinguían, b) se quedaban acantonadas en un refugio que le permitiese soportar las nuevas y adversas condiciones y c) evolucionaban -generalmente formando poliploides que tienen mayor plasticidad ecológica- y colonizaban esos nuevos ambientes.

Como en España hay infinidad de cadenas montañosas, depresiones cálidas, etc. hay también infinidad de hábitats diferentes y las plantas tuvieron como consecuencia infinidad de oportunidades para formar nuevas especies. Nuestra flora pues tiene elementos cosmopolitas, que viven en cualquier parte del mundo, elementos que llegaron del N, elementos atlánticos, elementos esteparios, elementos que llegaron de África, elementos mediterráneos y, por último, elementos que se han formado aquí y que viven aquí exclusivamente, es decir endemismos ibéricos. Esa diversidad es nuestra riqueza.

\section{Flora canaria}

Para comprender la flora canaria actual hemos de recurrir, al igual que hicimos con la de la Península, a un breve análisis de su origen, siempre teniendo en cuenta que nos encontramos en un archipiélago de origen volcánico, con notables peculiaridades geológicas y climáticas.

Los terrenos más antiguos del Archipiélago tienen una edad de 20 millones de años, mientras que los más recientes, las islas más jóvenes, parecen ser de hace 1,5 millones de años (La Palma) y hace 0,7 millones de años (isla del Hierro).

La flora canaria, como la flora de la Macaronesia -región insular que integra, Azores, Canarias Cabo Verde, Madeira e Islas Salvajes- parece haberse formado fundamentalmente a partir de la flora subtropical que crecía por Europa al final de la Era Terciaria. El registro fósil demuestra que muchas especies que crecían en el sur de Rusia y en la cuenca mediterránea son idénticas a algunas que se encuentran hoy en día en Canarias. Esos fósiles de especies que entonces crecían en toda Europa y Macaronesia se formaron posiblemente al final del Plioceno, cuando en Europa empezó a cambiar el clima y a desaparecer las condiciones de marcado carácter subtropical. Las mismas plantas pudieron sobrevivir en Canarias gracias a su clima más benigno 
(más cálido, más húmedo y con fuerte influencia oceánica), que causaron la extinción de las poblaciones europeas.

Al igual que los archipiélagos de Azores, Madeira y Cabo Verde, sin dejar de mencionar a las pequeñas islas de Salvajes, las Islas Canarias han soportado la invasión desde territorios próximos (África y Europa), de un grupo de plantas, en número impreciso, durante algunos millones de años. Una vez en el archipiélago, esas plantas llegadas de fuera empezaron a colonizar los diferentes hábitat, muchas simplemente se mantuvieron, pero otras han ido cambiando poco a poco adaptándose al nuevo ambiente y han llegado a formar nuevas especies dentro de las propias islas, especies que ya no han podido salir. Por medio de este proceso se llegaron a formar una gran cantidad de endemismos. Por ello en la flora canaria tenemos hoy tres grupos básicos de especies:

a) Las llegadas de fuera en sus orígenes. Nos referimos a los árboles de la conocida laurisilva como Laurus novocanariensis (laurel o loro), Persea indica (viñátigo), Ocotea foetens (tilo) o llex canariensis (acebo / acebiño), Juniperus turbinata (sabina), Pistacia atlantica (almácigo), Pistacia lentiscus (lentisco). Resulta curioso que muchas de las especies características hoy de Canarias, Madeira y Azores proceden del continente europeo, aunque en él ya se hayan extinguido. También llegadas de fuera, pero no del continente europeo sino del africano son los conocidos cardones y tabaibas, o especies leñosas del género Euphorbia.

b) Las especies que se formaron en las propias islas. Esta evolución fue tan fuerte que se formaron incluso grupos de especies muy diferente de sus ancestros protocolonizadores, como es el caso de los famosos tajinastes (numerosos especies llamativas del género Echium) o las margaritas (también numerosas especies de Argyranthemum), las cerrajas (id. del género Sonchus) etc. pero en otros casos la diversificación fue tan profunda que se Ilegaron a formar incluso nuevos géneros como es el caso de los 18 que hay endémicos de las islas, por ejemplo: Bystropogon, Semele (gilbalberas), Bencomia (rosal de guanche)y Marcetella (palo de sangre), Schizogyne (salado), que sólo existe en Canarias e Islas Salvajes.

c) Las recientemente traídas por el hombre de un modo accidental o voluntario. Aquí está incluida casi toda la flora de malas hierbas, flora de cunetas, etcétera.

\section{Peculiaridades: endemismos y xenófitos}

Uno de los parámetros más ampliamente utilizados para valorar la flora de un 30 territorio (país, región, etc.) es el que hace referencia al número de endemismos que 
contiene, de igual modo que el número de xenófitos -o especies foráneas recientemente llegadas- se viene utilizando para medir su nivel de degradación. Ambos parámetros son, en un principio, muy fáciles de comprender, pero tan pronto como se analizan un poco resultan muy complejos.

Utilizamos el término endémico en el sentido en que lo define el DRAE: "propio y exclusivo de determinadas localidades o regiones", y endemismo: "cualidad de endémico". Por tanto, si nos atenemos a esa definición, todas las plantas, excepto las cosmopolitas, serían endémicas, pues todo es cuestión de escala. Si tomamos un área muy extensa, incluiremos, lógicamente, a muchas más especies endémicas que si el área es reducida. Como decían C. Favarger y J. Contandriopoulos (1961) en su bello ensayo sobre el endemismo "es imposible definir con precisión la noción de endemismo porque es en sí misma relativa”. Se trata, según E. Sainz Ollero y J.C. Moreno Saiz, de un ejemplo típico al que resulta aplicable el aforismo de que es la escala la que crea el fenómeno.

En todo caso, los endemismos siguen siendo utilizados de un modo generalizado. Las razones según E. Sainz Ollero y J.C. Moreno Saiz serían las siguientes:

a) Las áreas ricas en endemismos pueden ser centros de especiación. Muchos estudios recientes sobre biodiversidad han puesto de manifiesto la coincidencia entre enclaves privilegiados por la endemicidad y por su riqueza en especies.

b) El endemismo es, a priori, un fenómeno relativamente excepcional, contrario a la dispersión de las especies.

c) Los táxones endémicos son generalmente especies raras, que a menudo exhiben fuertes adaptaciones y soluciones biológicas originales.

d) Los endemismos, con frecuencia, se encuentran en situaciones relícticas, en peligro de extinción.

En cualquier caso, siempre hay mucha controversia acerca del valor taxonómico de cierta cantidad de endemismos. Unos autores tienden a sobrevalorar las pequeñas diferencias que se observan en poblaciones locales y esto les da pie para describirlas como nuevos táxones que, evidentemente, se convierten en endemismos. Otros autores, por el contrario, prefieren hacer un enfoque más general, estudiar toda la variación en grandes áreas y no suelen describir las variantes locales.

De ahí viene la discrepancia en las cifras que se pueden encontrar cuando se consultan estudios que traten del tema. Por ejemplo, si nos fijamos en las obras clásicas de S.A. Cain o E.V. Wulff, podremos ver que según ellos la flora de Córcega 
tendría cerca del 50\% de sus plantas serían endémicas, pero otros autores más estrictos como Contandriopoulos o J. Gamisans \& D. ]eanmonod suponen que este porcentaje es del $8-11,5 \%$ respectivamente.

Las especies endémicas pueden tener dos orígenes contrapuestos. Unas son especies muy antiguas y muy ampliamente distribuidas, que debido a los cambios ambientales han ido desapareciendo, reduciendo su área, hasta quedar confinadas en un pequeño territorio, es decir son especies relícticas -también llamadas paleoendemismos o endemismos paleógenos-. Otras, por el contrario, son especies de más reciente formación que se han originado al adaptarse a unas condiciones muy concretas de un medio -llamados asimismo neoendemismos o endemismos neógenos-. Otros estudios basados primero en los trabajos citológicos y luego en los de biología molecular han permitido afinar más en la clasificación de los endemismos, pero eso escapa ya al alcance de este artículo. Esta es una de las razones por las que se valora más una especie de área muy reducida que una de área amplia. Esto distorsiona el uso de esos parámetros.

En cuanto a la densidades relativas de endemismos de algunos territorios próximos relacionados, diremos que las islas macaronésicas y mediterráneas destacan en los primeros lugares, seguidas de las penínsulas del entorno mediterráneo, siempre muy por encima de los países del centro y del norte de Europa. Las islas Canarias, con unos 550 endemismos $-32 \%$ de la flora total y aproximadamente el $50 \%$ de las plantas autóctonas-, aparecen en una situación privilegiada, consecuencia de su aislamiento, el clima relíctico, de tendencia subtropical, y su relieve acusado, que genera muy variados hábitats.

\section{NUESTRA FLORA EN COMPARACIÓN CON LA DE OTROS PAÍSES}

Hemos de advertir, en primer lugar, que cuando se pretende hablar de la riqueza florística expresada en número de especies o número de taxones (diversidad biológica tipo $\alpha$ ) no es posible -salvo en casos muy concretos- ofrecer cifras incuestionables, pues con frecuencia se dan casos en los que la identidad de una planta es dudosa -no se sabe si debe o no ser admitida- mientras que hay otros en los que la presencia de una especie determinada en el territorio es también dudosa por carencia de testimonio, por aparición ocasional, por extinción, o cualquier otra causa. No es de extrañar, por tanto, que no coincidan las cifras que ofrecen diferentes autores, a pesar de lo cual no debe pensarse que éstas tengan que ser necesariamente erróneas.

Una primera aproximación a esas cifras la podemos encontrar en el cuadro 1. Un primera ojeada nos permitirá acercarnos a las cifras que demuestran el valor de nuestra diversidad biológica en el mundo vegetal, según datos tomados de diversos autores y presentados con ocasión del simposio sobre "La flore du bassin méditerrenéen: essai de systématique synthétique" organizado por el C.N.R.S. en 


\section{CUADRO 1}

Riqueza florística de los países mediterráneos

\begin{tabular}{|l|c|}
\hline \multicolumn{1}{|c|}{ Países (autor) } & N. de especies \\
\hline España (E.F. Galiano) & C. 7.500 \\
\hline Portugal, Mad. y Azores (A.R. Pinto da Silva) & 3.117 \\
\hline Francia mediterránea (R. de Vilmorin) & c. 3.000 \\
\hline Italia (G. Moggi) & $5.500-6.000$ \\
\hline Grecia (Greuter \& al.) & C. 5.500 \\
\hline Turquía (P.H. Davis) & c. 8.000 \\
\hline Egipto y Libia (L. Boulos) & 2.085 \\
\hline Argelia y Túnez (P. Quézel \& D. Bounaga) & c. 3.300 \\
\hline Marruecos (C. Sauvage) & c. 4.200 \\
\hline
\end{tabular}

Fuente: Guinochet, M., Guittonneau, G. Ozenda, P., Quèzel, P. \& Sauvage, Ch. (eds.) 1975, “La flore du bassin méditerrenéen: assai de systématique synthétique» C.N.R.S., París, 1975.

(Las cifras, elaboradas hace 20 años, tienen pleno valor comparativo, pero no absoluto. Sobre los datos relativos a España véanse la estimaciones hechas al final del presente artículo.)

La comparación no se establece con los países atlánticos o centroeuropeos (Reino Unido, Alemania, Holanda, Bélgica, Escandinavia, etc.) porque casi todos estos tienen entre 1.200 y 2.000 especies, cifra muy baja frente a la de los países mediterráneos de una cierta extensión. La pobreza relativa de Egipto, Libia, etc. se debe a que en ellos la franja mediterránea es muy estrecha, ya que el desierto se aproxima mucho a la costa.

Lo que nos muestra este cuadro es que, sin duda, la flora española es la más rica de la Unión Europea por el número de especies vegetales conocidas hasta la fecha, lo que explica la amplia contribución de España a la biodiversidad y, también, la elevada responsabilidad que ello significa en cuanto a su protección y a su conservación.

\section{HACIA EL CONOCIMIENTO DE LA RIQUEZA REAL DE NUESTRA FLORA}

Pero, ¿cuál es la riqueza real de nuestra flora? En el cuadro 2 se muestran los datos que aportan las obras que han pretendido recopilar todas nuestras plantas vasculares, basándose, naturalmente, en la información disponible en el momento de su elaboración. Como podremos observar, las estimaciones son progresivamente crecientes; las obras más antiguas hacen una estimación más baja del número de especie que las más modernas. La más actualizada que podemos hacer se desprende de Flora ibérica, obra que ya estudió cerca del $60 \%$ de nuestras plantas vasculares, se recono- 
cieron 3.783 especies diferentes en España peninsular y Baleares. Si se incluyen también las subespecies, la cifra asciende a 4.292 taxones distintos. Si extrapolamos estos datos hasta el total, nos encontraremos con una cifra que ronda las 7.500 especies y subespecies sin contar las de Canarias, que tiene por su parte cerca de 2500 especies de plantas. Esto nos muestra que España, incluso sin contar las Islas Canarias, es el país más rico en diversidad biológica (plantas vasculares) de toda Europa y el Mediterráneo.

\section{CUADRO 2}

Nuestra diversidad florística

\begin{tabular}{|l|c|c|c|c|}
\hline & Willk. & Fl. Eur. & Elenc. & Checklist \\
\hline Especies & 5.089 & 5.250 & 5.926 & 5.597 \\
\hline Subesp. + vars. & 500 & 698 & 611 & 1.541 \\
\hline Totales & 5.900 & 5.948 & 6.537 & 7.138 \\
\hline
\end{tabular}

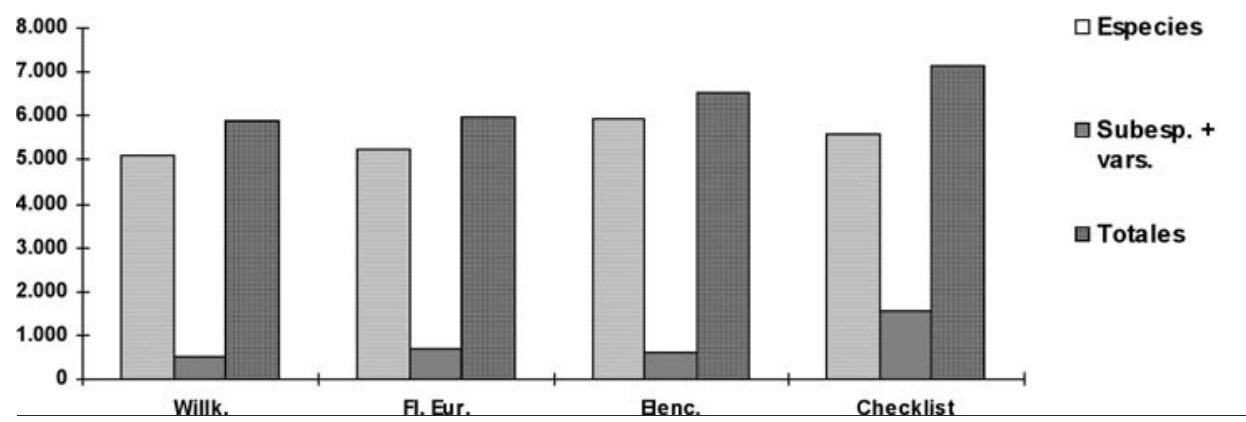

Fuentes:

Willk.: M. Willkomm \& J. Lange. 1961-1880. Prodromus florae hispanicae... 3 vols. Stuttgart. y M. WILLKOMM. 1893. Supplementum prodromi florae hispanicae. Stuttgart.

Fl. Eur.: Tutin \& al. (eds.). 1964-1980. Flora Europaea. 5 vols. Cambridge Univ. Press.

Elenc.: E. Guinea \& A. ceballos. 1978. Elenco de la flora vascular española. ICONA. Madrid.

Checklist: B. E. Smythies. 1984-1986. Flora o Spain and the Balearic Islands. Checklist of Vascular Plantas. Englera 32(1) \& 3(2). Berlín.

En el cuadro 3 se puede apreciar, por ejemplo, el ritmo de crecimiento de las novedades aportadas por el proyecto Flora Ibérica en los 14 volúmenes publicados, lo que da una idea, aunque parcial y limitada, de su utilidad para la ciencia y para la sociedad en general. 
CUADRO 3

Novedades taxonómicas y nomenclaturales dadas a conocer en Flora ibérica

\begin{tabular}{|l|r|r|r|r|r|r|r|r|r|r|r|r|r|r|r|r|}
\hline \multicolumn{1}{|c|}{ Volumen } & I & II & III & IV & V & VI & $\begin{array}{l}\text { VII } \\
\text { (I) }\end{array}$ & $\begin{array}{l}\text { VII } \\
\text { (II) }\end{array}$ & VIII & X & XIII & XIV & XV & XVIII & XXI & TotaI \\
\hline Sp. nov. & 8 & 5 & 33 & 1 & 2 & 53 & 9 & 2 & 2 & 0 & 2 & 1 & 5 & 1 & 0 & 124 \\
\hline Subsp. nov. & 3 & 9 & 2 & 3 & 3 & 0 & 0 & 2 & 1 & 7 & 0 & 0 & 0 & 0 & 0 & 30 \\
\hline Comb. sp. nov. & 1 & 1 & 16 & 15 & 1 & 0 & 11 & 0 & 0 & 1 & 2 & 1 & 1 & 0 & 1 & 51 \\
\hline Comb. subsp. nov. & 10 & 25 & 16 & 15 & 2 & 0 & 0 & 4 & 3 & 5 & 6 & 2 & 2 & 2 & 1 & 93 \\
\hline Total & 22 & 40 & 67 & 34 & 8 & 53 & 20 & 8 & 6 & 13 & 10 & 4 & 8 & 3 & 2 & 298 \\
\hline
\end{tabular}

Y en el cuadro 4 podemos apreciar el aumento de conocimiento que ello supuso con respecto al estado de la ciencia en España antes del inicio del proyecto. Tómese nota de que estas evaluaciones tienen en cuenta los resultados de menos de la mitad de lo que deberá ser el proyecto Flora Ibérica en su conjunto, por lo que es de esperar una rentabilidad social y científica mucho mayor al culminarlo.

Con ese alto índice de diversidad, para los ecólogos, agrónomos, forestales, etc. determinar plantas silvestres españolas -tarea imprescindible para muchos de sus trabajos- no era, ciertamente, un problema menor. A falta de una obra fiable, se veían en la obligación de recurrir a la ya clásica Flora Europaea (Cambridge 1964-1980), única obra de conjunto de toda Europa que incluye, naturalmente, nuestro territorio. Al usar esta herramienta, incorporan los errores propios de una obra tan general y se encuentran con dificultades adicionales.

Fue en estas circunstancias cuando en los años 80 del siglo pasado nació Flora ibérica como un proyecto nacional para cancelar, con la calidad exigible a aquellas alturas del siglo XX, la deuda histórica que el colectivo de botánicos tiene con la sociedad. No es, evidentemente, el proyecto más atractivo para un taxónomo, pues gran parte del trabajo ha de dedicarse a recopilar la muy abundante información ya publicada con anterioridad y a resumir lo ya conocido, pero sí el más urgente en la botánica española. En el cuadro 5 se aprecia la ingente base de registros sobre la que se desarrolla el proyecto.

Pero quizás lo más destacable fue la muy buena disposición de los taxónomos europeos a colaborar tanto en la redacción de las síntesis de los géneros de sus respectivas especialidades (autores), como en la revisión y corrección de los manuscritos (asesores). El cuadro 6 resume en cifras esta colaboración (entre paréntesis se hace figurar al número de países al que pertenece cada colectivo). 


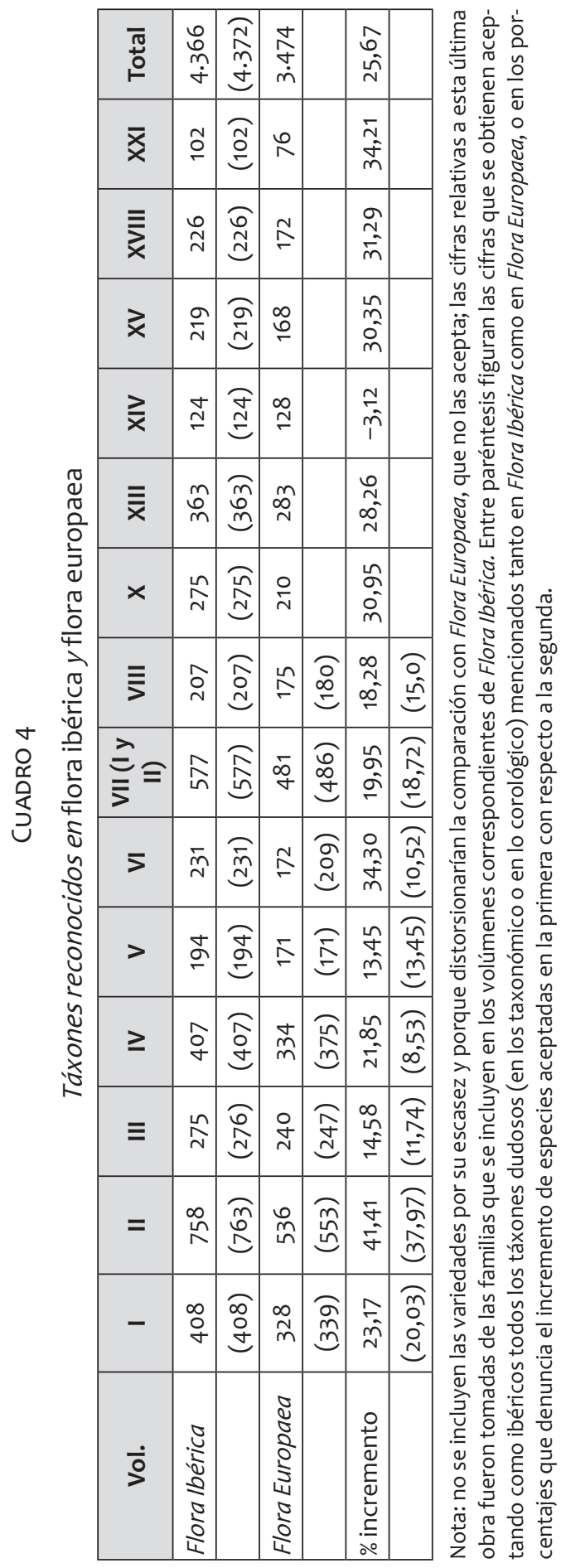


CUADRO 5

Bases de datos del proyecto flora ibérica

\begin{tabular}{|l|c|}
\hline \multicolumn{1}{|c|}{ Tipo } & Número de registros \\
\hline - Corológica & 1.050 .000 \\
\hline - Nombres vernáculos & 182.000 \\
\hline - Nomenclatura & 39.820 \\
\hline - Números de cromosomas & 10.275 \\
\hline - Autores de taxones & 3.650 \\
\hline - Libros y folletos & 3.205 \\
\hline - Revistas & 1.337 \\
\hline - Separatas & 4.050 \\
\hline
\end{tabular}

CUADRO 6

Investigadores que participan en el proyecto

\begin{tabular}{|c|c|c|c|}
\hline Volumen & Editores & Autores & Asesores \\
\hline I & $7(2)$ & $30(5)$ & $19(6)$ \\
\hline II & $7(2)$ & $49(9)$ & $32(9)$ \\
\hline III & $10(2)$ & $28(5)$ & $28(6)$ \\
\hline IV & $11(2)$ & $41(5)$ & $25(5)$ \\
\hline V & $7(2)$ & $13(3)$ & $30(5)$ \\
\hline VI & $7(2)$ & $15(2)$ & $32(2)$ \\
\hline VII (I y II) & $7(1)$ & $21(4)$ & $32(2)$ \\
\hline VIII & $7(2)$ & $19(3)$ & $33(5)$ \\
\hline X & $3(2)$ & $30(3)$ & $48(4)$ \\
\hline XIII & $4(1)$ & $16(3)$ & $48(2)$ \\
\hline XIV & $8(3)$ & $7(3)$ & $26(2)$ \\
\hline XV & $3(1)$ & $7(1)$ & $32(2)$ \\
\hline$X V I I I$ & $6(1)$ & $10(1)$ & $32(2)$ \\
\hline XXI & $2(1)$ & $15(1)$ & $37(3)$ \\
\hline
\end{tabular}

Nota: entre paréntesis se indica el número de países al que pertenecen los editores, autores o asesores.

Por lo que afecta al rendimiento del equipo y al ritmo de aparición de los volúmenes, a pesar de que una primera impresión apunta a un ritmo lento en la preparación y edición de las síntesis (descripción de las especies), la realidad es que se trabaja a un ritmo medio, en comparación con las más importantes floras del mundo elaboradas en esta segunda mitad del siglo XX. Y este análisis ha de hacerse teniendo en cuenta 
también otros factores, como el presupuesto (Flora ibérica tiene uno de los más bajos) y las dimensiones del equipo humano (este equipo, aun contando con gran apoyo internacional, es muy pequeño en comparación con el de Flora Neotropica, Flora of Autralia, Flora Malesiana, Flora Europaea, etc.).

\section{COROLARIO}

Lo que es fácil concluir a partir de este análisis es que por circunstancias geográficas y evolutivas, la flora española es enormemente diversa, de lo que deriva una gran riqueza, a pesar de que todavía la conozcamos de modo imperfecto. De todos modos, con los datos disponibles hasta el presente, podemos constatar que con más de 7500 especies en la Península y Baleares es la más rica de la Unión Europea y de la cuenca mediterránea. Si a ellas le sumamos las cerca de 2500 especies de la islas Canarias, esta extraordinaria riqueza se ve considerablemente acrecentada.

A pesar de ello y de estar en el siglo XXI nuestra riqueza vegetal es todavía insuficientemente conocida. En la actualidad, a través del esfuerzo en recursos humanos y financieros que nuestra sociedad dedica al proyecto Flora Ibérica, estamos en vías de completar ese conocimiento en un futuro próximo.

Es de esperar que riqueza y mejora del conocimiento vayan también acompasados de esfuerzo y acierto en las medidas de protección necesarias para conservar este inigualable e irremplazable tesoro natural de España que nuestra sociedad tiene la obligación de pasar al futuro en, al menos, las mismas condiciones que nuestra generación lo recibió. 